\title{
Como o aluno analisa uma crônica sem o narrador da história?
}

\author{
How does the student analyze a chronicle without the \\ narrator of the story?
}

Cómo el alumno analiza una crónica sin el narrador de la historia?

Diogo Fernando dos Santos ${ }^{1}$

\begin{abstract}
RESUMO: O presente artigo tem como objetivo ensinar a alunos do $5^{\circ}$ ano do Ensino Fundamental procedimentos de leitura a fim de que eles desenvolvam um comportamento leitor. Dessa forma, o intuito deste trabalho foi tornar observável para os alunos crônicas construídas com a presença ou não do narrador. Assim, foi necessário criar uma sequência de atividades com questões inferenciais que implicam, provavelmente, a tomada de consciência sobre o objeto de conhecimento. Para tanto, 0 trabalho está fundamentado na concepção interacionista sociodiscursiva (BAKHTIN, 2016; DOLZ; GAGNON; DECÂNDIO, 2010; SCHNEUWLY, 2004) e nas ideias de Vigotski (2007, 2009), ao discutir o processo da tomada de consciência e as relações de interação social que permitem o avanço significativo no aprendizado e no desenvolvimento do aluno, entre outros autores. Os resultados apontam que ao fazer boas intervenções, elas conduzem o aluno a refletir sobre o texto estudado, tornando observável os aspectos linguístico e notacional usados pelos autores. Em conclusão, ensinar os procedimentos de leitura permite que, posteriormente, o aluno possa fazer escolhas dos elementos que compõem uma narrativa para os seus próprios textos.
\end{abstract}

PALAVRAS-CHAVE: Crônica. Narrador. Atividades inferenciais. Tomada de consciência.

ABSTRACT: This article aims to teach reading procedures to students of the 5th grade of Elementary School, in order to make them develop a reader behavior. Therefore, the purpose of this work was to guide students to observe chronicles that were constructed with a narrator's presence or not. Thus, it was necessary to create a sequence of activities with inferential questions that probably imply the awareness of the object of knowledge. For that, this work is based on the sociodiscursive interactionist conception (BAKHTIN, 2016; DOLZ; GAGNON; DECÂNDIO, 2010; SCHNEUWLY, 2004) and Vygotsky's ideas (2007, 2009). It also discusses the process of awareness and the social

\footnotetext{
${ }^{1}$ Mestrando em Linguística Aplicada pela Universidade de Taubaté. Especialista em Gramática e Uso pela Universidade de Taubaté e Alfabetização: relação entre ensino e aprendizagem pelo Instituto Vera Cruz.
} 
interaction relations, which allows a significant advance in student learning and development, besides other authors. The results show that, when good interventions are done, these interventions lead the students to think about the studied text, making them to observe the linguistic and notational aspects used by authors. In conclusion, the teaching of the reading procedures allows the students to make choices about the elements that make up a narrative for their own texts later.

KEYWORDS: Chronicle. Narrator. Inferential activities. Awareness.

RESUMEN: El presente artículo tiene como objetivo enseñar a los alumnos de $5^{\circ}$ de nivel fundamental procedimientos de lectura con el din de que ellos desenvuelvan un comportamiento lector. De esta forma, la intención de este trabajo fue tornar observable para los alumnos las crónicas construidas con la presencia o no del narrador. Así, fue necesario crear una secuencia de actividades con preguntas inferenciales que implican, probablemente, la toma de conciencia sobre el objeto de conocimiento. Por ello, el trabajo está fundamentado en la concepción interaccionista socio-discursiva (BAKHTIN, 2016; DOLZ; GAGNON; DECÂNDIO, 2010; SCHNEUWLY, 2004) y en las ideas de Vygotsky (2007, 2009), al discutir el proceso de toma de conciencia y las relaciones de interacción social que permiten el avance significativo en el aprendizaje y en el desarrollo del alumno, entre otros autores. Los resultados muestran que, al realizar buenas intervenciones, ellas conducen al alumno a reflexionar sobre el texto estudiado, tornando observable los aspectos lingüísticos y notacional usados por los autores. En conclusión, enseñar los procedimientos de lectura permite que, posteriormente, el alumno pueda realizar elecciones de los elementos que componen una narrativa para sus propios textos.

PALABRAS-CLAVE: Crónica. Narrador. Actividades inferenciales. Toma de conciencia.

\section{Introdução}

Este artigo relata uma pesquisa sobre procedimentos de leitura e de escrita voltados para alunos do $5^{\circ}$ ano do Ensino Fundamental. A motivação para esse estudo foi a prévia familiaridade com o assunto e o ensejo de pesquisar e aprender mais, ao analisar o que seriam boas intervenções de ensino que colaboram significativamente no avanço da aprendizagem do aluno. É fato que escrever bem exige de um escritor uma série de operações mentais e físicas que o mobilizam ao elaborar o seu texto escrito. Essa mobilização vai desde o planejamento das ideias até a revisão do conteúdo escrito e sua apresentação. Além disso, a escrita precisa ser clara e, se for de cunho comunicativo, requer identificar o leitor ideal, o gênero que caracteriza a obra, o lugar de circulação, o 
portador e o veículo de divulgação. Essas são etapas de construção importantes do planejamento para que o material escrito chegue, de fato, ao leitor ideal. (DOLZ; GAGNON; DECÂNDIO, 2010).

No entanto, para chegar a esses procedimentos o aluno-escritor também precisa ter consciência do seu papel como leitor para apropriar-se com autonomia dos recursos estilísticos de uma obra lida para compor os seus próprios textos. Assim, o leitor-escritor consegue discernir qual a exata finalidade do trabalho escrito. Essa finalidade está ligada aos objetivos que impulsionam o escritor a escrever, ou seja, o texto escrito serve para divertir, informar ou emocionar o leitor? Isso exige do escritor um conhecimento sobre o gênero discursivo a respeito do que se propõe a escrever diante de tantas finalidades existentes, além das três citadas. $\mathrm{E}$ tal conhecimento o escritor pode descobrir enquanto leitor assíduo.

Sobre o comportamento leitor, para maiores esclarecimentos, Lerner (2002, p. 62, grifo da autora) explica que são ações praticadas pelo leitor, as quais the permite de forma crítica e autônoma agir sobre o material lido, sendo capaz de:

[...] recomendar o que se leu, compartilhar a leitura, confrontar com outros leitores as interpretações geradas por um livro ou uma notícia, discutir sobre as intenções implícitas nas manchetes de certo jornal [...] Entre os mais privados, por outro lado, reler um fragmento anterior para verificar o que se compreendeu, quando se detecta uma incongruência, saltar o que não se entende ou não interessa e avançar para compreender melhor, identificar-se com o autor ou distanciar-se dele assumindo uma posição crítica, adequar a modalidade de leitura exploratória ou exaustiva, pausada ou rápida, cuidadosa ou descompromissada[...] - aos propósitos que se perseguem e ao texto que se está lendo $[\ldots]$

Assim, levar em conta a escolha do narrador, o tempo verbal, a descrição dos personagens, a sequência temporal, o espaço, o emprego dos recursos notacionais da língua e a construção dos diálogos, são fatores importantes na construção de um texto literário. Esses são alguns dos recursos que tornam a obra ficcional uma escrita singular. O domínio sobre tais quesitos pode ser aprendido pelo aluno de forma sistemática, ensinado pelo professor. Isso se dá 
por meio da interação, a qual permite a tomada de consciência do aluno sobre o processo de produção textual. Assim, valemo-nos de um registro a respeito de uma ação positiva que possibilita analisar os questionamentos pertinentes feitos por este professor-pesquisador junto a alunos do $5^{\circ}$ ano do Ensino Fundamental.

Por essa razão, nosso objetivo, dentro de uma proposta de produção textual, é ensinar os procedimentos de leitura para os alunos, a fim de que eles desenvolvam um comportamento leitor. Para isso, selecionamos para a discussão deste trabalho, o papel do narrador em crônicas. A partir de uma sequência de atividades, as quais pretendemos apresentar neste artigo, discutimos quais foram os questionamentos feitos aos alunos que implicaram, provavelmente, uma tomada de consciência sobre o objeto de aprendizagem daquele momento. Para tanto, utilizamos como fundamento a concepção interacionista sociodiscursiva (BAKHTIN, 2016; DOLZ; GAGNON; DECÂNDIO, 2010; SCHNEUWLY, 2004), como também nos apoiamos nas ideias de Vigotski $(2007,2009)$, ao discutir 0 processo da tomada de consciência e as relações de interação social que permitem o avanço significativo no aprendizado e no desenvolvimento do aluno, entre outros autores.

$\mathrm{Na}$ construção deste estudo, recorremos à abordagem qualitativa de pesquisa para fazer a apresentação da sequência de atividades em forma de um relato analítico, contendo respostas dadas por alunos sobre os questionamentos feitos por este professor-pesquisador. Esse trabalho foi realizado com alunos do $5^{\circ}$ ano do Ensino Fundamental, de uma escola pública municipal do interior paulista. Consideramos que o detalhamento dessas atividades contribuirá para 0 aperfeiçoamento de docentes que buscam entender melhor os caminhos para ensinar a produção textual para esses alunos.

\footnotetext{
${ }^{2}$ Ao longo do texto, é usada a grafia do nome do autor dessa forma "Vigotski". No entanto, de acordo com outra obra consultada, também é assinalada a grafia "Vigotsky", nas citações e na referência.
} 


\section{Da Tomada de Consciência no Aluno e sua Interação Social}

Consideramos importante explanar sobre o conceito da tomada de consciência discutido por Vigotsky (2009), porque nos possibilita argumentar a respeito dos caminhos tomados na elaboração dos exercícios para os alunos. Também nos dá condições de pensar sobre suas respostas, buscando meios para interagir com elas, que vai desde sinalizar uma informação no texto, inserir uma nova informação até reelaborar a pergunta feita pela criança a fim de que ela pense e responda o que busca saber.

Por essa razão, propomos exercícios (relacionados ao assunto), os quais permitem que os alunos escrevam, como também reflitam a respeito dessas atividades e dialoguem com os demais colegas sobre o texto escrito. Acreditamos, de acordo com Oliveira (1992), referendada em Vygotsky, que as funções mentais superiores são ações desencadeadas pelo indivíduo de forma consciente, elas fazem parte de processos voluntários e de mecanismos intencionais. Ou seja, o indivíduo internaliza tais funções mediante a apropriação da cultura em que está inserido. Na escola, essas funções são desenvolvidas, de preferência, pelo ensino formal, sistematizado nos conteúdos escolares. Por isso, precisamos saber o que os alunos pensam sobre o que produziram no decorrer do texto escrito.

Para Vigotski (2007), as funções no desenvolvimento da criança ocorrem de duas formas: no nível social e, posteriormente, no nível individual. isto é, para o autor, o desenvolvimento se origina nas relações reais entre indivíduos humanos. Primeiro há esse contato entre pessoas, depois uma ação ocorre dentro do próprio indivíduo. Assim, para o autor, a tomada de consciência "se baseia na generalização dos próprios processos psíquicos que redunda em sua apreensão. Nesse processo manifesta-se em primeiro lugar o papel decisivo do ensino" (VIGOTSKY, 2009, p. 290).

Silva e Abud (2017, p. 156), referenciadas nas ideias de Vigotski (2001), explicam que "a tomada de consciência e consequentemente o domínio intencional de determinada operação arbitrária ocorre mediante o 
desenvolvimento dos conceitos científicos, pois são estes que garantem uma sistematização hierárquica de conceitos." A partir do exposto, observamos que o aluno ao realizar determinadas operações sobre os aspectos formais da língua, de forma voluntária, demonstra que nele já ocorreu a tomada de consciência. Desse modo, o aluno é capaz de pensar sobre e explicar aquilo que fez e como o fez. Segundo Vigotsky (2009) a dominação de uma função é adquirida na medida em que ela é internalizada pelo sujeito.

Portanto, quando tais atividades foram desenvolvidas para trabalhar o gênero crônica com os alunos, estabelecemos como critério atividades com questões inferenciais, as quais pudessem ser desafiadoras para eles. Queríamos que houvesse essa tomada de consciência a fim de levá-los a argumentar suas respostas e, ao mesmo tempo, avançar nas atividades posteriores.

Em suas investigações psicológicas, ao tratar da questão da interação entre aprendizagem e desenvolvimento intelectual, Vigotsky (2009, p. 322) fez as seguintes descobertas: "que a aprendizagem está sempre adiante do desenvolvimento, que a criança adquire certos hábitos e habilidades numa área específica antes de aprender a aplicá-los de modo consciente e arbitrário". Por essa razão, o autor argumenta que o aprendizado na criança ocorre antes mesmo do aprendizado escolar, pois são nas interações sociais que ela adquire condições de se desenvolver. É no seio familiar que a criança aprende a falar, a imitar os adultos e até mesmo a se apropriar de um repertório de habilidades. Consequentemente, cabe à escola a função de sistematizar esses conhecimentos espontâneos trazidos pela criança em conhecimentos científicos.

Para Vigotski (2007), quando a criança recebe assistência de outros no processo de aprendizado é algo muito mais indicativo para o seu desenvolvimento mental do que simplesmente fazer por si mesma. Dessa maneira, criou o conceito de Zona de Desenvolvimento Proximal (ZDP), o qual envolve aquilo que a criança não sabe fazer sozinha, mas consegue fazer com o auxílio de outros. Daí os avanços que podem acontecer, por meio das intervenções fornecidas pelo professor, pelos colegas e pela participação em atividades conjuntas e colaborativas. 
Schneuwly (2004, p. 39, grifo do autor) reafirma essas ideias e observa que

Para o interacionismo social, a consciência de si e a construção das funções superiores são estritamente dependentes da história de relações do indivíduo com sua sociedade e da utilização da linguagem. $O$ fato de pertencer a uma comunidade de interpretação das unidades de representação permite a compreensão e a antecipação das atividades de outrem; permite, igualmente, a modificação de seu próprio comportamento, levando-se em conta o ponto de vista do outro.

Desse modo, o autor vai ao encontro das ideias de Vigotski (2007) e discute que a aprendizagem intencional ocorre, frequentemente, dentro de uma instituição de ensino e o desenvolvimento do aluno implica construções sociais. Menciona o aprendizado da linguagem formal que se dá mediante o ensino escolar, pois nesse espaço ocorre a conscientização dos objetivos relativos à produção e à compreensão, devido à cooperação social, a qual é "[...] o fator determinante das transformações e dos progressos que ocorrem." (SCHNEUWLY, 2004, p. 38).

Schneuwly (2004) considera a proposta de aprendizagem descrita por Dolz (1994), na qual o desenvolvimento da autonomia do aluno está intermediado primeiro pelas relações sociais, pois segundo o autor:

O objetivo primeiro é o de instrumentalizar o aprendiz para que ele
possa descobrir, com seus camaradas, as determinações sociais das
situações de comunicação assim como o valor das unidades linguísticas
no quadro de seu uso efetivo. Nessa segunda opção estratégica, as
intervenções sistemáticas do professor desempenham um papel central
para a transformação das interações entre o aprendiz e o texto.
(SCHNEUWLY, 2004, p. 40, grifo do autor).

Portanto, acreditamos na interação entre parceiros e professor. Dessa forma, essa foi uma das estratégias que utilizamos tanto para avaliar o que sabiam e como expunham por meio da fala e da escrita suas opiniões a respeito das questões levantadas, quanto para nos autoavaliar e perceber se essas atividades estavam sendo realmente desafiadoras. 


\section{O Gênero Crônica}

O trabalho com o gênero crônica ocorreu durante o terceiro bimestre do ano letivo, com dezenove alunos do $5^{\circ}$ ano do Ensino Fundamental. Dois quesitos foram fundamentais para iniciar esse assunto com os alunos. Primeiro, porque já havíamos trabalhado com eles as características e a estrutura dos contos literários, isso facilitaria introduzir o assunto, acentuando as semelhanças e diferenças entre os dois gêneros. Segundo, porque algumas alunas relataram que diariamente escreviam suas rotinas num blog que era compartilhado com os demais colegas da escola. Esse comentário foi a condição necessária para compartilharmos com todos uma forma diferente de escrever para o blog, além do relato que faziam.

Antes de especificarmos o gênero crônica literária e comentarmos sobre as questões inferenciais criadas nos exercícios para os alunos, é preciso definir o que se caracteriza por gênero discursivo. Bakhtin (2016) elucida que o uso da linguagem transita em qualquer campo da atividade humana e "o emprego da língua efetua-se em forma de enunciados (orais e escritos) concretos e únicos, proferidos pelos integrantes desse ou daquele campo da atividade humana." (BAKHTIN, 2016, p. 11). Por essa razão, esses enunciados possuem condições específicas e finalidades próprias em seu uso, assim, cada enunciado contém um conteúdo temático, um estilo e uma construção composicional e ocorrem dentro de uma determinada situação comunicativa.

[...] estão indissoluvelmente ligados no conjunto do enunciado e são igualmente determinados pela especificidade de um campo da comunicação. Evidentemente, cada enunciado particular é individual, mas cada campo de utilização da língua elabora seus tipos relativamente estáveis de enunciados, os quais denominamos gêneros do discurso. (BAKHTIN, 2016, p. 12).

Bakhtin (2016) ciente da heterogeneidade dos gêneros do discurso, falado ou escrito, atentou-se em diferenciar os gêneros como primários e secundários. Os primários, de caráter simples, oriundos das conversações espontâneas, ligados diretamente à vida cotidiana, possuem uma ligação direta com o contexto 
social no qual estão inseridos. Os de ordem secundária, estão relacionados à complexidade de sua elaboração, carregados de certa carga cultural, são predominantemente escritos, como os romances, os textos científicos, os contos, as crônicas.

Segundo Candido (1992), a crônica, especificamente a brasileira, antes de se tornar um gênero associado a publicações de jornal, originou-se dos folhetins escritos no século XIX por grandes escritores como José de Alencar, Machado de Assis, entre outros. Esses folhetins eram artigos de rodapé que abordavam assuntos do dia, como políticos, artísticos e literários. Eram de caráter informativo, porém, aos poucos, os assuntos comentados foram sendo deixados de lado, assumindo a finalidade de divertir o leitor. Com o passar do tempo, esse gênero ganhou um tom mais ligeiro, encurtou o tamanho do texto e as narrativas passaram para uma linguagem mais leve e descompromissada com o leitor, chegando ao que de fato é hoje, a crônica. Candido (1992) comenta que houve um afastamento do discurso argumentativo que a crônica abordava, passando a penetrar o campo da poesia, o que considerou como uma fórmula moderna, "onde entra um fato miúdo e um toque humorístico, com o seu quantum satis de poesia, representa o amadurecimento e o encontro mais puro da crônica consigo mesma." (CANDIDO, 1992, p. 15, grifo do autor).

Pelo fato de a crônica transmitir seus dizeres de forma leve e acessível, Candido (1992) explica que há nesse ato comunicativo mais do que um estudo intencional sobre o lado humano do homem e sua vida cotidiana. Enfatiza que é possível o ensino por meio das crônicas pois "[...] aprende-se muito quando se diverte, e aqueles traços constitutivos da crônica são um veículo privilegiado para mostrar de modo persuasivo muita coisa que, divertindo, atrai, inspira e faz amadurecer a nossa visão das coisas" (CANDIDO, 1992, p. 19).

Tanto Candido (1992), quanto Sá (1997), mencionados por Siebert (2014), comentam que a crônica por muito tempo foi vista como um gênero menor. Isso se dava justamente por se tratar de um texto escrito na efervescência do funcionamento de um jornal, cuja produção está vinculada a um discurso jornalístico, que tem como objetivo relatar os acontecimentos do dia e assim 
organizá-los e apresentá-los com diferentes versões, conforme explica Siebert (2014) referenciada em Mariani (1998). Para Candido (1992), mesmo a crônica não sendo um gênero de efeito maior, assim como é o romance, ela traz algo especial, ao aproximar o escritor da realidade cotidiana do leitor, o que

[...] para muitos pode servir de caminho não apenas para vida, que ela serve de perto, mas para a literatura. [...] Por meio dos assuntos, da composição aparentemente solta, do ar de coisa sem necessidade que costuma assumir, ela se ajusta à sensibilidade de todo o dia. (CANDIDO, 1992, p. 13).

E sobre essa narrativa de todo o dia, um leitor atento vai aos poucos percebendo, nesse faz de conta, que o narrador introduz verdades muito parecidas com as dele, desejos comuns e situações até mesmo semelhantes, permitindo que o leitor se identifique com o rápido relato. Ainda como observa Siebert (2014, p.681), o gênero crônica permite que o cronista, ao trabalhar no desenvolvimento de um texto em curto prazo, relatando o cotidiano que são marcas características do discurso jornalístico, também adentre no discurso da literatura para trabalhar o texto com componentes ficcionais e poéticos.

Neste estudo, convém discutir a função do narrador no gênero crônica, pois é sobre esse elemento que pretendemos trabalhar uma sequência de atividades devidamente organizada e planejada para alunos do $5^{\circ}$ ano do Ensino Fundamental. Assim, à luz das explicações de Proença Filho (1992), uma narrativa literária pode ser realizada

[...] por um narrador não participante ou por um personagem que convive com os outros na história narrada. Isso nos leva ao modo como esta última se apresenta e se constrói: o ângulo de visão, ponto de vista, foco ou enfoque narrativo, também conhecidos como visão da narrativa. (PROENÇA FILHO, 1992, p. 46).

O autor comenta que há outras possibilidades de a história ser narrada, podendo o discurso narrativo ser feito na primeira pessoa. Igualmente, realizada por um personagem secundário, bem como narrada em terceira pessoa, por um narrador que não faz parte da trama da história, no entanto ele tem um 
conhecimento total do assunto. Também é possível contar o que conhece de apenas um personagem ou de forma superficial, narrar o que conhece sobre todos os personagens. Portanto, neste trabalho, o que pretendemos levar para os alunos são crônicas com características semelhantes na temática, com estruturas parecidas, construídas por meio de diálogos e narrativas com narrador e sem narrador. $E$ isso nos permitiu discutir com os alunos: o que torna observável identificar quando o texto literário tem narrador e quando não tem?

\section{Sobre as Questões Inferenciais}

O fenômeno da compreensão se dá quando o indivíduo faz uso das noções inferenciais, assim esclarece Coscarelli $(2002,2003)$. Para a autora, o conceito de inferência está ligado às operações cognitivas que possibilitam ao leitor construir novas informações sobre o texto oral ou escrito. No entanto, não são quaisquer contribuições feitas que serão traduzidas como inferência, é preciso levar em conta que, ao acrescentar um dado a respeito do que está sendo lido ou ouvido, o próprio texto permitirá esses acréscimos, para que não haja erros sobre a leitura, afastando os sentidos compatíveis com o texto (COSCARELLI, 2003). Vargas (2015) concorda com essa afirmação, ao observar que nos primórdios dos estudos sobre inferências acreditava-se que elas estavam ligadas diretamente ao texto e toda informação inferida fazia jus aos seus termos implícitos. Sua tese gira em torno de um conceito de inferência voltada para um processo de interação entre um leitor que funde seus conhecimentos prévios com as informações trazidas pelo texto, assim, recriando novos significados sobre ele.

Segundo Marcuschi (1999), o ato de saber inferir implica os conhecimentos adquiridos do leitor que lhes ajudarão a compreender melhor o texto e a interagir com ele. A justificativa é que a leitura envolve atividades cognitivas, as quais abrangem noções semânticas, pragmáticas, lógicas e culturais. $O$ ato de ler passa por um processo de seleção, em que o leitor avança em suas predições, ao mesmo tempo em que recua para fazer correções sobre as hipóteses levantadas, sem haver linearidade para isso. O leitor e autor travam uma interação 
comunicativa com base no texto, visto que "[...] os conhecimentos individuais afetam decisivamente a compreensão, de modo que o sentido não reside no texto." (MARCUSCHI, 1999, p. 96).

Vargas (2015) acrescenta que a inferenciação em leitura tem suas raízes nas ciências da cognição e defende que isso "[...] se trata de um construto cognitivo básico e constitutivo da leitura como processo. Sob essa visão o leitor geraria inferências de forma apenas a entender o que está escrito quando as informações do texto lido não fossem suficientes." (VARGAS, 2015, p. 315).

Segundo Coscarelli (2002) não há uma sistematização para nomear as inferências, por isso, também se torna difícil classificá-las. Assim, é feito uma divisão das inferências, de um lado as conectivas e do outro as elaborativas. Estas enriquecem o texto com informações sem estabelecer vínculos de coerências; aquelas já estabelecem coerência entre diferentes partes do texto, ou seja, "[...] quando uma determinada informação só pode ser ligada a outra por meio de uma operação inferencial são conectivas. Caso elas não sejam feitas, haverá problemas na compreensão do texto." (COSCARELLI, 2002, p. 4).

Com base na fundamentação apresentada, relatamos a sequência de atividades desenvolvidas com os alunos do Ensino Fundamental.

\section{O Desenvolvimento da Atividade}

$\mathrm{Na}$ primeira etapa da elaboração dos exercícios, definimos o nosso propósito didático que foi estudar os recursos linguístico e notacional usados pelos autores nas crônicas literárias que tomamos como objeto de ensino. Isso se deu para sinalizar ao leitor quando há narrador e quando não há narrador em um texto escrito. Assim, estabelecemos alguns critérios que pudessem nos nortear na construção desses exercícios, criando uma tabela de expectativas sobre o que os alunos já sabiam e o que deveriam aprender. 
Quadro 1 - Sondagem

\begin{tabular}{|c|l|}
\hline $\begin{array}{c}\text { O que os alunos já } \\
\text { sabiam? }\end{array}$ & $\begin{array}{l}\text { Conseguiam identificar a finalidade de um texto literário lido; } \\
\text { Conseguiam discutir o sentido da pontuação em textos bem escritos; } \\
\text { Descreviam os aspectos comportamental e físico dos personagens dos } \\
\text { textos lidos; } \\
\text { Conheciam os verbos de dizer (verbos dicendi). }\end{array}$ \\
\hline $\begin{array}{c}\text { O que os alunos } \\
\text { precisavam } \\
\text { conhecer? }\end{array}$ & $\begin{array}{l}\text { Aprofundar o olhar sobre o narrador de uma crônica literária, } \\
\text { certificando-se de que há textos em prosa que não necessitam de um } \\
\text { narrador. } \\
\text { Observar e justificar como as marcações linguística e notacional são } \\
\text { feitas por bons escritores. }\end{array}$ \\
\hline $\begin{array}{c}\text { Por que os alunos } \\
\text { deveriam conhecer as } \\
\text { crônicas literárias? }\end{array}$ & $\begin{array}{l}\text { Ampliar o repertório, ao escrever seus textos, tomando ciência de que } \\
\text { um texto pode ser construído com ou sem narrador. }\end{array}$ \\
\hline $\begin{array}{c}\text { Em qual momento os } \\
\text { alunos escreveriam? }\end{array}$ & $\begin{array}{l}\text { Os alunos estudam os textos, respondem os exercícios por escrito e } \\
\text { depois verbalizam fazendo suas considerações sobre o que foi escrito. } \\
\text { A última etapa é a construção de uma crônica que relate um fato do } \\
\text { seu dia a dia, com a possibilidade de publicá-la no blog de uma das } \\
\text { alunas da sala. }\end{array}$ \\
\hline
\end{tabular}

Fonte: Elaboração do autor

Selecionamos as crônicas literárias, depois de ter nos aprofundado sobre o que os alunos já sabiam e o que precisariam conhecer, de acordo com Vigotski (2007). Escolhemos a série Para Gostar de Ler, da Editora Ática, v. 1. Adotamos três autores para essa empreitada, Fernando Sabino (2003), Rubem Braga (2003), Paulo Mendes Campos (2003), porque todos tinham como conteúdo temático comum (BAKHTIN, 2016), (DOLZ; GAGNON; DECÂNDIO, 2010) meninos como personagem principal.

$\mathrm{O}$ assunto foi introduzido junto aos alunos mediante diversos tipos de textos que foram trabalhados na sala de aula. Levamos jornais e revistas que traziam a crônica literária. Comentamos que identificaríamos a forma como esses textos bem escritos haviam sido redigidos, observando os assuntos que eram abordados pelos cronistas. Como vimos, era uma forma de apropriação do

\footnotetext{
${ }^{3}$ Com isso fomos ao encontro da teoria de Lerner (2002) ao aproveitar o nosso tempo didático, trabalhando por meio de uma modalidade organizativa, o projeto. Essa modalidade nos permitiu envolver a leitura num contexto mais significativo, a qual está articulada a um propósito claro para o aluno, tendo um produto final elaborado por ele.
} 
conteúdo estudado com o intuito de que, posteriormente, pudessem escrever crônicas para o blog dos colegas de sala.

$\mathrm{Na}$ continuidade, os alunos leram em duplas e apresentaram suas considerações sobre o que tinham achado dos textos lidos. Desse modo, solicitamos que contassem rapidamente o teor da história para que todos pudessem, adiante, entender o que perguntaria. A pergunta principal feita a eles foi: $O$ que esses textos lidos têm em comum? As respostas dos alunos mencionados são representações das respostas dos demais alunos.

Aluno 1: Esses textos falam de pessoas e eles contam o que está acontecendo com elas...

Fizemos uma nova pergunta: Observem nos textos de vocês... vamos discutir um pouco sobre o tempo desses acontecimentos que envolvem os personagens. Existe uma hora, ou dias para o que está acontecendo?

Aluno 2: Aqui, cita que aconteceu com ele no dia 22 de janeiro...

Aluno 3: Eu entendi que acontece tudo no mesmo dia.

Outras perguntas foram feitas ao longo da discussão a respeito do que poderia ser uma crônica literária e, sempre por meio dos exemplos dados pelos alunos, conseguimos criar uma lista de diferenças e semelhanças com o conto literário. Mostrar jornais e revistas como uns dos veículos principais de divulgação desse gênero, também foi importante para que os alunos pudessem perceber a construção presente nesse gênero (BAKHTIN, 2016). Precisavam entender que a trama central envolve poucos personagens, que as histórias poderiam ser curtas, que $o$ assunto poderia girar em torno de algum acontecimento comum, do dia a dia de qualquer pessoa (CANDIDO, 1992).

A partir desse primeiro contato com esse gênero, apresentamos a série Para Gostar de Ler, que reunia diversas crônicas de vários escritores que escreviam para jornais e que, nesse livro, estavam reunidas algumas das melhores. Iniciamos a atividade em dupla, entregando para cada uma o texto Continho de Paulo Mendes Campos. Os alunos relataram suas primeiras impressões, classificando-o como um texto divertido. Descreveram as formas 
física e comportamental do personagem. Depois escreveram sobre a primeira consigna dada: Peguem o lápis de vocês e circulem o que seria a fala do narrador.

Uma das intervenções feitas a uma aluna durante a realização dessa atividade foi:

Professor: Por que você marcou essas duas linhas, o que chamou a sua atenção?

Aluno 1: Geralmente, os diálogos são separados por travessão, aqui ele separa bem o diálogo dos personagens usando a outra linha.

Professor: Você disse geralmente... posso dizer que nem sempre usamos travessão para marcar a fala dos personagens?

Aluno 1: Não... a gente já leu textos em que os diálogos vinham marcados com aspas e apareciam até no meio do texto... seria o pensamento do personagem.

Para outro aluno:

Professor: E você, como separou a fala do personagem da fala do narrador?

Aluno 2: Primeiro ele começa com era uma vez, está na terceira pessoa, daí eu observei que quando o personagem vai falar ele usa a primeira pessoa.

Precisávamos ter certeza se todos os alunos haviam compreendido que a forma como conjugamos os verbos indica a pessoa do discurso. Por isso, inserimos para todos uma nova consigna:

Professor: Descreva como é o narrador da história, leve em consideração se ele participa ou não do que está sendo narrado.

Aluno 1: O narrador participa da história descrevendo o local e o que o menino estava pensando. A história não fala sobre o narrador.

Aluno 2: O narrador não participa da história, ele apenas narra o que está acontecendo com o menino.

Aluno 3: Ele usa a terceira pessoa, se fosse com ele diria que ele era o menino.

Voltamos a questionar o primeiro aluno que afirma que o narrador participa da história. 
Professor: Quero que você busque no texto e diga o que o fez acreditar que o narrador participa da história.

Aluno 1: Na primeira parte... Era uma vez um menino magro, triste e barrigudinho...

Permitimos que outro aluno comentasse o que havia sido lido.

Aluno 2: Ele não participa... ele só conta a história do menino. Era uma vez um menino magro, triste e barrigudinho... não quer dizer que é com ele. Ele não está na história. Ele conta em terceira pessoa, conta sobre o menino.

Fizemos uma nova intervenção para que ficasse claro que o narrador não conta sua própria história:

Professor: vamos pensar assim: para que ele participasse da história como poderia ficar então?

Aluno 3: Eu me lembro daquele dia em que conheci um menino magro, triste e barrigudinho.

Aluno 4: Eu era um menino magro, triste e barrigudinho... Caso ele seja o personagem da história.

Para que os alunos desenvolvessem seus conhecimentos a respeito do conteúdo estudado e elaborassem, posteriormente, as próprias crônicas, era preciso que houvesse os agrupamentos sociais. Esses agrupamentos proporcionariam o aprendizado do conteúdo, pois acreditávamos que o conhecimento seria construído na interação do professor com os alunos e entre os próprios alunos (VIGOSTSKI, 2007).

Pretendíamos que o aluno compreendesse o texto, tomando-o para si, como se fosse dele a obra escrita para que pudesse criar sobre o que estava pronto, inserindo novas informações (COSCARELLI, 2003), possibilitando com isso entender o texto e assim tirar suas próprias conclusões. No caso apresentado, pretendíamos ainda que os alunos elaborassem suas estratégias de verificação para discutir se esse texto narrativo estaria na primeira ou terceira pessoa do discurso. Quando sugerimos a mudança do discurso, desejávamos observar a forma como o aluno manipularia essa construção. Acreditamos que também isso foi possível acontecer porque os alunos vieram ao longo do ano 
letivo apropriando-se de um conhecimento novo e organizando-o. Essa tomada de consciência (VIGOSTKI, 2007) não ocorreu numa simples sinalização feita em uma única aula, foi um processo contínuo de revisitações do conteúdo ministrado.

Feita essa atividade e verificado que grande parte dos alunos havia compreendido quando o narrador conta a história participando dela e quando simplesmente narra um fato que ocorreu com alguém. Doravante, era preciso avançar com novas consignas para que chegássemos de fato à análise literária de um texto sem narrador.

Figura 1 - Observações de um aluno

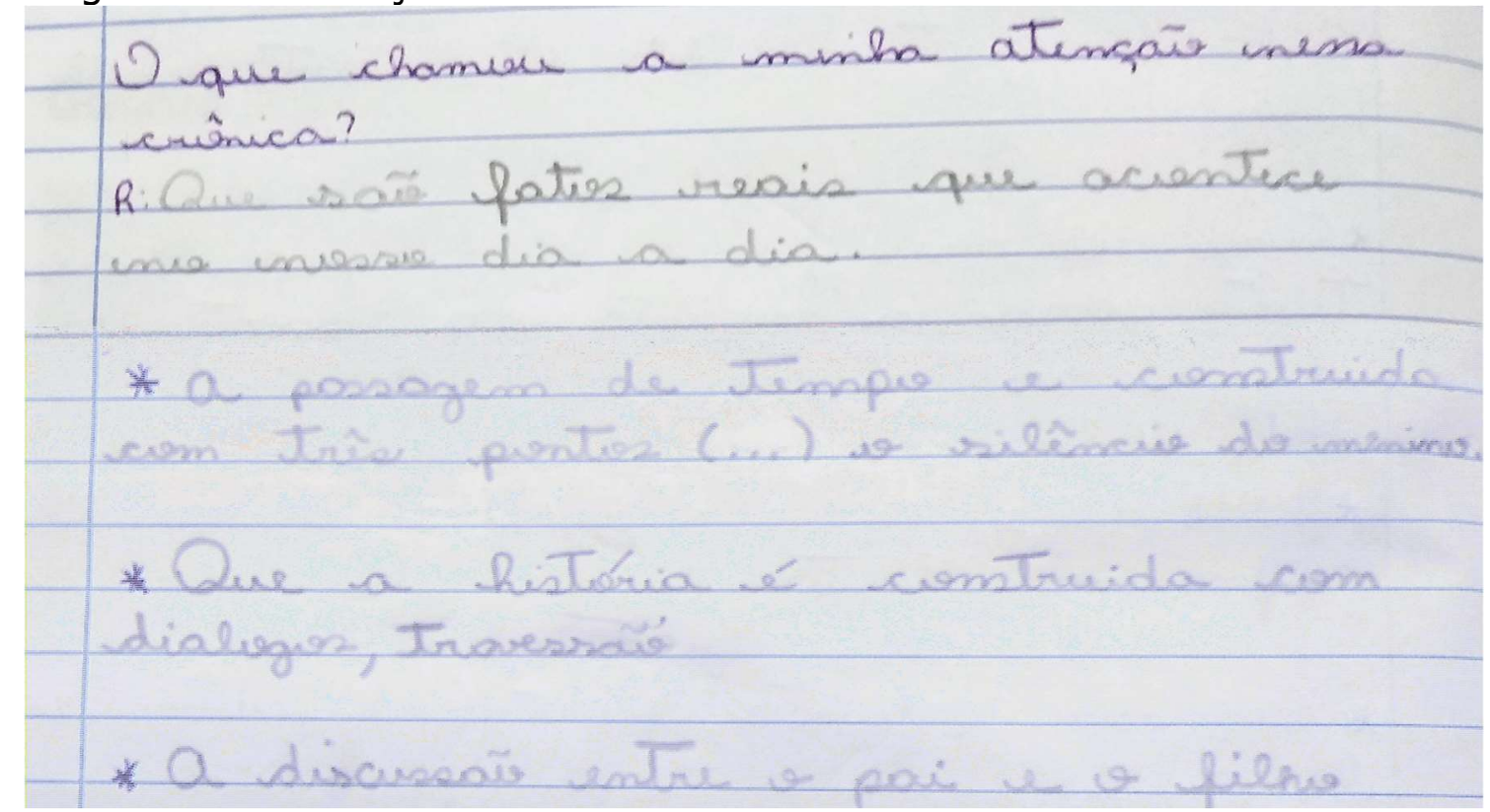

Fonte: Acervo do autor.

Por essa razão, entregamos dois textos, um de Fernando Sabino, Hora de dormir, e o outro de Rubem Braga, Negócio de menino. Sinalizamos dois objetivos para essa leitura, no primeiro, seria ler e escrever tudo o que havia chamado a atenção. No segundo, descrever os dois meninos das duas histórias. Primeiro texto discutido: Hora de dormir.

Quando os alunos socializaram suas impressões sobre o texto lido, consideramos a seguinte observação apontada por um deles: a passagem de tempo é construída com três pontos (...) o silêncio do menino. Aproveitamos a oportunidade para questioná-los: Por que o autor ao invés de escrever o menino 
se silenciou, ou, alguns minutos depois ele voltou a falar, ele achou melhor colocar três pontos? Os alunos não responderam de imediato. Pedimos para que lessem o segundo texto, Negócio de menino e que fizessem uma lista do que havia de diferente entre as duas histórias ${ }^{4}$.

Aluno 1: A primeira história é construída só com diálogos.

Alunos 2: No segundo texto, o narrador participa da história, ele fala do encontro dele com o filho de um amigo.

Aluno 3: Em Hora de dormir, o autor para dar uma pausa utiliza três pontos. Já em Negócio de dormir, ele usa a palavra pausa.

Fizemos um novo questionamento: Vocês saberiam dizer porque no texto de Fernando Sabino, Hora de dormir, ele usa três pontos ao invés de ter escrito como o outro autor a palavra pausa?

Aluno 1: Por que não tem narrador, por isso, o texto é construído só com diálogos.

Perguntamos novamente: Se tivesse narrador, como ficaria essa passagem?

Aluno 1: Eu colocaria assim: e com medo de responder para o pai o menino ficou em silêncio.

Lançamos uma nova pergunta: Você disse que o texto não tem narrador por isso ele é construído só com diálogos, podemos dizer que isso ocorre também no texto Negócio de Menino? Afinal de contas ele também é construído com diálogos.

Aluno 1: Sim, mas em Negócio de menino o narrador aparece e participa da história... Aqui, olha: Tem dez anos, é filho de um amigo, e nos encontramos na praia...

Em outro momento, levamos um trecho de Hora de dormir para que eles pudessem analisar o uso das vírgulas usadas pelo autor. Pedimos para que lessem o trecho escolhido e depois explicassem o que haviam entendido, qual

\footnotetext{
${ }^{4}$ Outras informações foram ditas, mas para este artigo citaremos apenas o que diz respeito ao narrador da história.
} 
era o sentido que a vírgula dava ao texto, já que consideraram que essa crônica não havia narrador.

Trecho escolhido:

Quadro 2 - Trecho da crônica Hora de dormir

- Ora, deixe de conversa. Vamos desligar esse negócio. Pronto, acabou-se. Agora é tratar de dormir.

- Chato.

- Tome, para você aprender. E amanhã fica de castigo, está ouvindo? Para aprender a ter respeito a seu pai.

Fonte: Sabino (2003)

A consigna dada foi: algumas ações são praticadas durante o diálogo construído. Encontre isso e comente a respeito.

Figura 2 - Considerações de um aluno a respeito da leitura feita

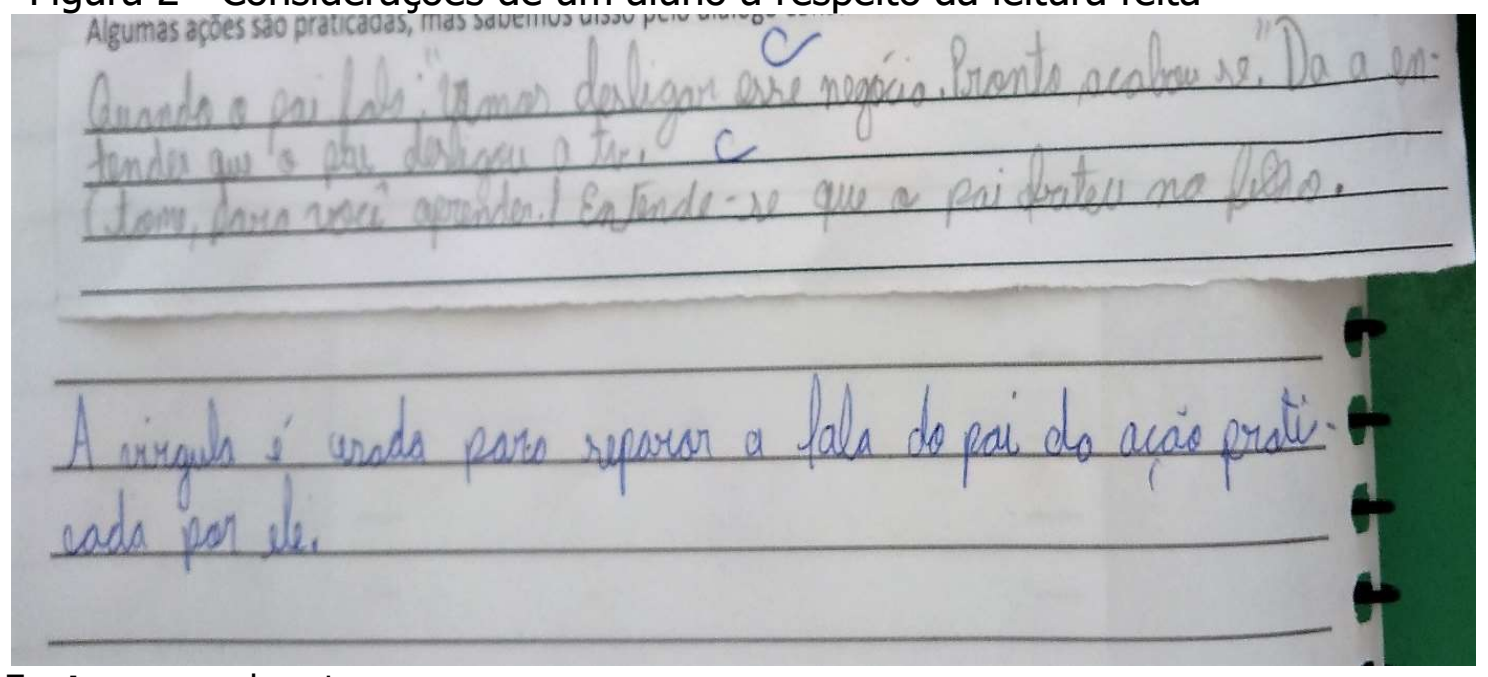

Fonte: acervo do autor

Os alunos concluíram que por não haver narrador o escritor teria que sinalizar para o leitor as ações que ocorriam durante o diálogo, observaram que isso foi feito com o uso da pontuação. Pedimos para que eles voltassem no texto de Rubem Braga e que discutissem as ações marcadas pelo narrador, uma forma de sistematizar o conteúdo que se tornou observável para eles.

Aluno 1: Aqui no final, professor: Longa pausa. Hesitação. A irmãzinha o chama de dentro d'água. E, antes de sair correndo, propõe, sem me encarar:

- O senhor não me dá um passarinho de presente, não? 
Aluno 2: Aqui nesse pedaço: - Dez contos.

Pausa. Depois volta:

- Só tem coleira?

Foi interessante ver a forma como os alunos discutiam o uso da vírgula empregada pelo autor e saber que essa foi uma das estratégias usadas por ele na construção dessa história. Comentaram que havia uma passagem de tempo entre o pedir para desligar a televisão, em seguida, dizer pronto acabou-se e que a vírgula fazia essa separação. Comentaram também que Rubem Braga não usou os verbos de dizer no meio das falas dos personagens.

\section{Algumas Considerações}

Quando apresentamos o quadro 1, Sondagem, e analisamos, a partir de nossas observações em sala de aula, os conteúdos que deveriam ser ajustados para aquela série/ano do Ensino Fundamental, sabíamos que a execução desses conteúdos não seria uma tarefa fácil. Pautamo-nos exatamente em traçar uma rota de trabalho que pudéssemos contemplar aquilo que os alunos ainda não dominavam. Durante a elaboração do registro do nosso planejamento, demos valor ao que Lerner (2002) explica acerca da questão da gestão do tempo em relação à quantidade de conteúdos a serem ministrados. Para autora,

\footnotetext{
Quando se opta por apresentar os objetos de estudo em toda sua complexidade e por reconhecer que a aprendizagem progride através de sucessivas reorganizações do conhecimento, o problema da distribuição do tempo deixa de ser simplesmente quantitativo: não se trata somente de aumentar o tempo ou de reduzir os conteúdos, tratase de produzir uma mudança qualitativa na utilização do tempo didático. (LERNER, 2002, p. 87).
}

Na continuidade, a escolha desse projeto, uma modalidade organizativa, foi ao encontro do nosso objetivo. Não queríamos apenas que tornasse observável para os alunos textos escritos com narrador e, outros, sem narrador. Queríamos que fizessem uso do que conseguiram extrair das análises feitas das 
crônicas apresentadas para que, posteriormente, escrevessem suas próprias crônicas e as publicassem.

É certo que, para construção das atividades, foi preciso ouvir os discentes, conectar a sua realidade, saber suas limitações e propor desafios que os alunos seriam capazes de resolver. Dessa forma, sabíamos que para a assimilação desse complexo conteúdo seria preciso pensar em agrupamentos, em registrar as ideias discutidas e em socializar com todos os registros feitos pelas duplas. Enfim, a interação social e as perguntas potencializadoras feitas pelo professor seriam as estratégias mais adequadas como metodologia de trabalho.

É preciso evidenciar também que as respostas orais e escritas apresentadas pelos alunos vão ao encontro do que expomos acerca das funções mentais superiores. Saber o que os alunos pensam sobre o que produziram no decorrer do texto, foi importante para essa pesquisa. Chegamos a uma conclusão de que criar a oportunidade de os alunos exporem suas ideias, seria o caminho mais adequado. Por essa razão, as atividades de ler com objetivos claros e definidos, comparar as semelhanças e as diferenças existentes entre crônicas apresentadas e a discutir os elementos linguísticos e notacionais empregados pelos autores contribuíram para que 0 aluno ordenasse internamente esse novo conhecimento adquirido.

\section{Referências}

BAKHTIN, Mikhail. Os gêneros do discurso. Organização, tradução, posfácio e notas de Paulo Bezerra. Notas a edição russa de Serguei Botcharov. São Paulo: Editora 34, 2016.

BRAGA, Rubem. Negócio de menino. In: ANDRADE, Carlos Drummond de, SABINO, Fernando; MENDES CAMPOS, Paulo; BRAGA, Rubem. Crônicas 1. São Paulo: Ática, 2003, v. 1, p. 21-23. (Para gostar de ler).

CAMPOS, Paulo Mendes. Continho. In: ANDRADE, Carlos Drummond de, SABINO, Fernando; MENDES CAMPOS, Paulo; BRAGA, Rubem. Crônicas 1. São Paulo: Ática, 2003. v. 1, p. 85. (Para gostar de ler). 
CANDIDO, Antonio. A vida ao rés-do-chão. In: CANDIDO, Antonio. A crônica: o gênero, sua fixação e suas transformações no Brasil. Campinas, SP: Editora da Unicamp; Rio de Janeiro: Fundação Casa de Rui Barbosa, 1992. p. 13-22.

COSCARELLI, Carla Viana. Inferência: afinal o que é isso? Belo Horizonte: FALE/UFMG, 2003. Disponível em: http://bbs.metalink.com.br/ icoscarelli/publica.htm. Acesso em: 22 maio 2017.

COSCARELLI, Carla Viana. Reflexões sobre as inferências. In: CONGRESSO BRASILEIRO DE LINGUÍSTICA APLICADA, 6., 2002, Belo Horizonte. Anais ... Belo Horizonte: UFMG, 2002. 1 CD-ROM.

DOLZ, Joaquim; GAGNON, Roxane; DECÂNDIO, Fabrício. Produção escrita e dificuldades de aprendizagem. Tradução de Fabrício Decândio e Anna Rachel Machado. Campinas, SP: Mercado de Letras, 2010.

LERNER, Délia. Ler e escrever na escola: o real, o possível e o necessário. Porto Alegre: Artmed, 2002.

MARCUSCHI, Luiz Antônio. Leitura como processo inferencial num universo cultural-cognitivo. In: BARZOTTO, Valdir Heitor (org.). Estado de leitura. Campinas, SP: Mercado de Letras, 1999.

OLIVEIRA, Marta Kohl de. O problema da afetividade em Vygotsky. In: LA TAILLE, Yves de; OLIVEIRA, Marta Kohl de; DANTAS, Heloysa. Piaget, Vygotsky, Wallon: teorias psicogenéticas em discussão. São Paulo: Summus, 1992. p. 75-84.

PROENÇA FILHO, Domício. A linguagem literária. São Paulo: Ática, 1990.

SABINO, Fernando. Hora de dormir. In: ANDRADE, Carlos Drummond de, SABINO, Fernando; MENDES CAMPOS, Paulo; BRAGA, Rubem. Crônicas 1. São Paulo: Ática, 2003. v. 1, p. 11-14.

SCHNEUWLY, Bernard. Gênero e tipos de discurso: considerações psicológicas e ontogenéticas. In: SCHNEUWLY, Bernard; DOLZ, Joaquim. Gêneros orais e escritos na escola. Tradução de Roxane Roxo e Glaís Sales Cordeiro. Campinas, SP: Mercado de Letras, 2004.

SIEBERT, Silvânia. A crônica brasileira tecida pela história, pelo jornalismo e pela literatura. Linguagem em (Dis)curso LemD, Tubarão, SC, v. 14, n. 3, p. 675-685, set./dez. 2014. Disponível em:

http://www.scielo.br/pdf/ld/v14n3/1518-7632-ld-14-03-00675.pdf. Acesso em: 8 jun. 2018.

SILVA, Elisabeth Ramos da; ABUD, Maria José Milharezi. A apreensão de aspectos morfossintáticos que iluminam os sentidos do gênero poema. Revista Diadorim, Rio de Janeiro, v. 19, n. 2, p. 153-168, jul./dez. 2017. Disponível em: 
https://revistas.ufrj.br/index.php/diadorim/article/view/9959. Acesso em: 10 jun. 2018.

VARGAS, Diego da Silva. Por uma visão cognitivista do processo de inferenciação em leitura. Ciências \& Cognição, Rio de Janeiro, v. 20, n. 2, p. 313-330, 2015. Disponível em: http://www.cienciasecognicao.org. Acesso em: 14 maio. 2018.

VIGOTSKI, Lev Semenovich. $A$ formação social da mente: o desenvolvimento dos processos psicológicos superiores. Tradução de José Cipolla Neto, Luís Silveira Menna Barreto e Solange castro Afeche. 7. ed. São Paulo: Martins Fontes, 2007.

VIGOTSKY, Lev Semenovich. A construção do pensamento e da linguagem. Tradução de Paulo Bezerra. 2. ed. São Paulo: Martins Fontes, 2009. 